\title{
Dispersion of dielectric permittivity and magnetic properties of solid solution PZT-PFT*
}

 \\ ${ }^{1}$ University of Silesia, Faculty of Computer Science and Materials Science, Materials Science Department, 2 Sniezna St., \\ 41-200 Sosnowiec, Poland \\ ${ }^{2}$ University of Silesia, Institute of Physics, 4 Uniwersytecka St. 40-007 Katowice, Poland
}

\begin{abstract}
In this paper we present the results of investigations into ceramic samples of solid solution $(1-\mathrm{x})\left(\mathrm{PbZr}_{0.53} \mathrm{Ti}_{0.47} \mathrm{O}_{3}\right)-$ $\mathrm{x}\left(\mathrm{PbFe}_{0.5} \mathrm{Ta}_{0.5} \mathrm{O}_{3}\right)$ (i.e. $\left.(1-\mathrm{x}) \mathrm{PZT}-\mathrm{xPFT}\right)$ with $\mathrm{x}=0.25,0.35$ and 0.45 . We try to find the relation between the character of dielectric dispersion at various temperatures and the composition of this solution. We also describe the magnetic properties of investigated samples. With increasing the content of PFT also mass magnetization and mass susceptibility increase (i.e. magnetic properties are more pronounced) at every temperature. The temperature dependences of mass magnetization and reciprocal of mass susceptibility have similar runs for all the compositions. However, our magnetic investigations exhibit weak antiferromagnetic ordering instead of the ferromagnetic one at room temperature. We can also say that up to room temperature any magnetic phase transition has not occurred. It may be a result of the conditions of the technological process during producing our PZT-PFT ceramics.
\end{abstract}

Keywords: multiferroic; ferroelectric; antiferromagnetic; relaxor; ceramics

(C) Wroclaw University of Technology.

\section{Introduction}

$\mathrm{Pb}\left(\mathrm{Fe}_{0.5} \mathrm{Ta}_{0.5}\right) \mathrm{O}_{3}$ (PFT) belongs to perovskite structure materials with a general formula $\mathrm{Pb}\left(\mathrm{B}^{\prime} \mathrm{B}^{\prime}\right) \mathrm{O}_{3} \cdot \mathrm{Fe}^{3+}$ is a magnetic ion while $\mathrm{Ta}^{5+}$ is a nonmagnetic one. These ions are randomly distributed at $\mathrm{B}$ positions of perovskite structure what leads to ferroelectric relaxor properties. Below $220 \mathrm{~K}$ this material is monoclinic with a space group of $\mathrm{Cm}$, at the temperature range of $220 \mathrm{~K}<\mathrm{T}<270 \mathrm{~K}$ it is tetragonal (P4mm), while above $270 \mathrm{~K}$ it is cubic $\mathrm{Pm} \overline{3} \mathrm{~m}$ [1]. PFT undergoes two successive diffuse ferroelectric phase transitions which take place at about $270 \mathrm{~K}$ and $220 \mathrm{~K}$ [2] and in addition, two antiferromagnetic transitions, one of which is reported in the range of 133 to $180 \mathrm{~K} \mathrm{[3]}$ and the other at $9 \mathrm{~K}$ [4-6]. Magnetic investigations exhibit the absence of ferromagnetism in conventional PFT at any temperature.

\footnotetext{
${ }^{*}$ This paper was presented at III Polish-Lithuanian-Ukrainian Meeting on Ferroelectrics Physics, Wroclaw, 2014.

${ }^{\dagger}$ E-mail: ryszard.skulski@us.edu.pl
}

In the solid solution $(1-\mathrm{x})\left(\mathrm{PbZr}_{0.53} \mathrm{Ti}_{0.47} \mathrm{O}_{3}\right)-$ $\mathrm{x}\left(\mathrm{PbFe}_{0.5} \mathrm{Ta}_{0.5} \mathrm{O}_{3}\right) \quad$ (i.e. $\left.\quad(1-\mathrm{x}) \mathrm{PZT}-\mathrm{xPFT}\right)$, $\mathrm{Zr} / \mathrm{Ti} / \mathrm{Fe} / \mathrm{Ta}$ ions occupy $\mathrm{B}$ positions of perovskite structure, but such notation underlines that proportion between $\mathrm{Fe}^{3+}$ and $\mathrm{Ta}^{5+}$ must be equal to $1 / 1$. Therefore, another possibility of notation of the chemical formula of the compound is $\mathrm{Pb}\left[\left(\mathrm{Zr}_{0.53} \mathrm{Ti}_{0.47}\right)_{1-\mathrm{x}}\left(\mathrm{Fe}_{0.5} \mathrm{Ta}_{0.5}\right)_{\mathrm{x}}\right] \mathrm{O}_{3}$. For $\mathrm{x}=0.1$ to 0.4 this solid solution exhibits saturated ferroelectric hysteresis loops with saturation polarization about 25 to $40 \mu \mathrm{C} / \mathrm{cm}^{2}$ and square saturated magnetic hysteresis loops with magnetization $0.1 \mathrm{emu} / \mathrm{g}$ at $295 \mathrm{~K}$ (i.e. weak ferromagnetism) [7-9]. It means that PZT-PFT belongs to the class of materials known as multiferroics. Moreover, PZT-PFT is the lowest-loss room-temperature multiferroic known [7, 9]. Such materials are very interesting for magnetoelectric devices.

The possible reason of the presence of weak ferromagnetism in the solid solution $(1-\mathrm{x}) \mathrm{PZT}-$ $\mathrm{xPFT}$ with $\mathrm{x}=0.2$ to 0.4 can be the fact that the PZTs near the morphotropic boundary have 
essentially higher piezoelectric coefficients at room temperature.

Ceramic samples investigated in this paper have been obtained using a conventional ceramic technology and the results of main investigations such as: XRD, EDS, SEM of microstructure as well as dielectric properties and P-E hysteresis loops were described in [10]. The main aim of this paper is an investigation of dielectric dispersion phenomena using Cole-Cole plots and investigations of magnetic properties of PZT-PFT solid solution.

\section{Samples and experiment}

Ceramic samples of the solid solution $(1-\mathrm{x})\left(\mathrm{PbZr}_{0.53} \mathrm{Ti}_{0.47} \mathrm{O}_{3}\right)-\mathrm{x}\left(\mathrm{PbFe}_{0.5} \mathrm{Ta}_{0.5} \mathrm{O}_{3}\right) \quad(\mathrm{ab}-$ breviated as PZT-PFT) with $\mathrm{x}=0.25,0.35$ and 0.45 have been obtained from simple oxides: $\mathrm{PbO}, \mathrm{ZrO}_{2}, \mathrm{TiO}_{2}, \mathrm{Fe}_{2} \mathrm{O}_{3}$ and $\mathrm{Ta}_{2} \mathrm{O}_{5}$. The powders were milled using a planetary mill FRITSCH Pulverisette 6 , in ethanol for $12 \mathrm{~h}$. The synthesis of the mixed powders was carried out under the following conditions: $\mathrm{T}_{\text {synth }}=850{ }^{\circ} \mathrm{C}, \mathrm{t}_{\text {synth }}=10 \mathrm{~h}$, while the final sintering (densification) was conducted at $\mathrm{T}_{\mathrm{s}}=1350{ }^{\circ} \mathrm{C} / \mathrm{t}_{\mathrm{s}}=4 \mathrm{~h}$ using the pressureless sintering method. The main aim of the technology was to obtain a single phase PZT-PFT solid solution in the form of ceramic samples. Details of the technology were presented in [10].

Below we describe the analysis of dielectric and magnetic measurements. Measurements of magnetization were performed using QD MPMS-XL7 SQUID magnetometer. The temperature dependence of magnetization $\mathrm{M}(\mathrm{T})$ was measured in the applied magnetic field $\mathrm{H}$ after zero field cooling (ZFC) and after field cooling (FC). The magnetic hysteresis loops $\mathrm{M}-\mu_{0} \mathrm{H}$ were measured using the maximum field $\mu_{0} \mathrm{H}=8 \mathrm{~T}$.

\section{Results and discussion}

The results of XRD tests, SEM investigations of microstructure and EDS investigations of chemical composition were presented in [10]. Analyzing XRD patterns it has been stated that all samples at the room temperature have a perovskitetype structure as the dominating structure, with a small amount of an unwanted foreign phase (pyrochlore phase). Microstructural studies have shown that with increasing $\mathrm{x}$ in PZT-PFT solid solution the average size of grains decreases and wider distribution of grain diameters is observed. Results of EDS investigations confirm that the compositions of obtained samples are close to the assumed ones.

\subsection{Dielectric measurements}

Main results of dielectric measurements we have also presented in [10]. With increasing $\mathrm{x}$ the temperature of the maximum of dielectric permittivity shifts towards lower temperatures and samples with $\mathrm{x}=0.25$ and $\mathrm{x}=0.35$ exhibit low values of dielectric losses up to temperature of about $100{ }^{\circ} \mathrm{C}$. For $\mathrm{x}=0.25$ a sharp phase transition from ferroelectric phase to the paraelectric one has been observed with high values of dielectric permittivity. The composition with $\mathrm{x}=0.35$ has slightly lower values of dielectric permittivity at maximum. In the case of $\mathrm{x}=0.45$ PFT the values of dielectric permittivity are much lower, and the phase transition takes place in a wider range of temperature. It has been stated that samples with $\mathrm{x}=0.25$ and $\mathrm{x}=0.35$ exhibit low values of dielectric losses up to temperature of about $100{ }^{\circ} \mathrm{C}$. Dielectric losses for $(1-\mathrm{x}) \mathrm{PZT}-\mathrm{xPFT}$ samples with $\mathrm{x}=0.45$ are much higher.

Fig. 1 shows the plots of the real part ( $\varepsilon^{\prime}$ ) versus the imaginary part ( $\varepsilon ")$ of the complex permittivity, i.e. Cole-Cole plots for PZT-PFT solid solutions (at the temperature range from $30{ }^{\circ} \mathrm{C}$ to $150{ }^{\circ} \mathrm{C}$ ) and for frequencies from $100 \mathrm{~Hz}$ to $1 \mathrm{MHz}$. It is seen that with increasing $\mathrm{x}$ the character of ColeCole plots change is very different. In the sample with $\mathrm{x}=0.25$ we practically do not see dispersion of dielectric permittivity. On the other hand, in the sample with $\mathrm{x}=0.45$ at the low frequency part of the Cole-Cole plot, a semicircle is clearly visible and there are much higher values of $\varepsilon$ ' and $\varepsilon "$. Therefore, we can say that with increasing content of PFT the character of dielectric dispersion in solid solution PZT-PFT changes evidently. 


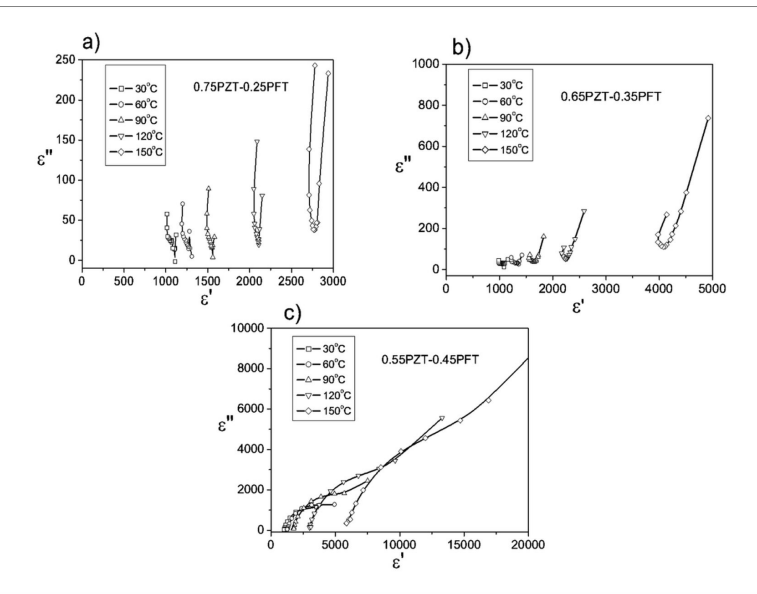

Fig. 1. Cole-Cole plots below $\mathrm{T}_{\mathrm{m}}$ for $(1-\mathrm{x}) \mathrm{PZT}-\mathrm{xPFT}$ below $150{ }^{\circ} \mathrm{C}$. (a) $\mathrm{x}=0.25$, (b) $\mathrm{x}=0.35$, (c) $\mathrm{x}=0.45$.

\subsection{Magnetic measurements}

PZT-PFT solid solutions have low values of mass magnetization and the temperature dependences of mass magnetization have similar runs (Fig. 2). With increasing temperature it is observed a significant decrease in the value of mass magnetization. The plots in Fig. 2 also show that with increasing PZT content in $(1-x)$ PZT-xPFT, the values of reciprocal of mass susceptibility increase. In the studied range of temperature up to room temperature no ferromagnetic phase transition is observed.
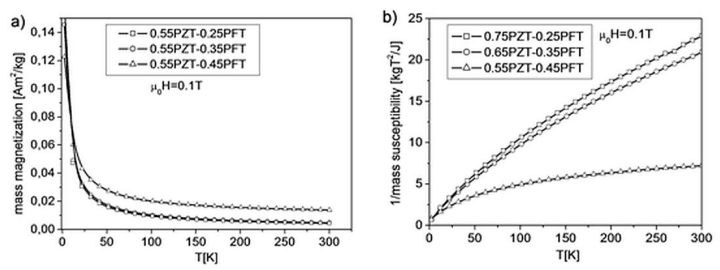

Fig. 2. Dependence of mass magnetization (a) and reciprocal of mass susceptibility (b) on temperature for all investigated samples.

The dependences of mass magnetization on magnetic field in a wide range of temperatures and magnetic fields show similarity for all samples (Fig. 3a, 3c, 3e). In Fig. 3b, 3d, 3f there are presented enlarged central parts of Fig. 3a, 3c, 3e. At higher temperatures the slight differences are observed and the values of mass magnetization decrease. However, for the sample $0.55 \mathrm{PZT}-0.45 \mathrm{PFT}$ an anomaly is seen (Fig. 3f) which can be interpreted as weak antiferromagnetism. This situation is similar to the one described in [7] but in that work a weak ferromagnetism was observed in samples with $\mathrm{x}=0.3$ and $\mathrm{x}=0.4$. It may be a result of conditions of the technological process during producing the PZT-PFT ceramic samples.
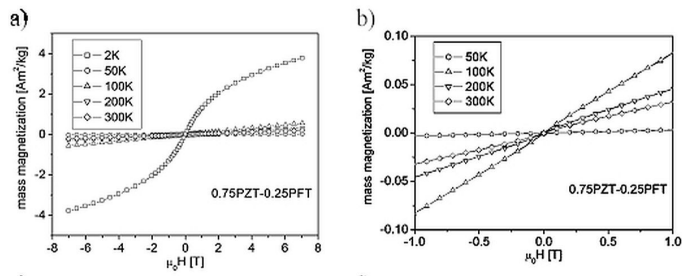

c)
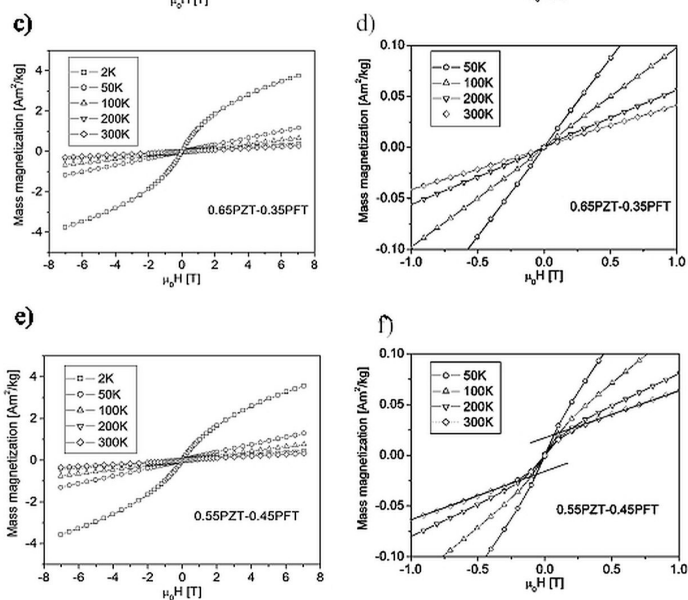

Fig. 3. Dependence of mass magnetization on magnetic field at various temperatures. Graphs (b), (d), (f) are enlarged parts of graphs (a), (c), (e).

\section{Conclusions}

The dispersion of dielectric permittivity in the sample $0.55 \mathrm{PZT}-0.45 \mathrm{PFT}$ is clearly of a different nature than in the other samples. In case of magnetic properties, permeability dispersion in this sample is typical of relaxors. The weakest dispersion was observed in a sample of $0.75 \mathrm{PZT}-$ $0.25 \mathrm{PFT}$, which is a normal ferroelectric and has the highest $\mathrm{T}_{\mathrm{C}}$ temperature between all investigated samples. It is seen from Fig. 2 that 
with increasing the content of PFT, the mass magnetization and mass susceptibility increase at every temperature (i.e. magnetic properties are more pronounced). The temperature dependences of mass magnetization and reciprocal of mass susceptibility have similar runs for all compositions. However, unlike to works $[8,9]$, the results of our magnetic investigations do not exhibit ferromagnetic ordering at room temperature but rather weak antiferromagnetism for $\mathrm{x}=0.45$. We can also say that up to room temperature any magnetic phase transition has not occurred. It may be a result of the conditions of the technological process during producing our PZT-PFT ceramics.

As a conclusion of our work [10] and this work we can say that all investigated compositions exhibit normal ferroelectric hysteresis loops at room temperature. For $\mathrm{x}=0.25$ sharp phase transition from ferroelectric phase to paraelectric one and high values of dielectric permittivity are observed. Composition PZT-PFT with $\mathrm{x}=0.45$ has the lowest values of dielectric permittivity at maximum, and the transition is more diffused. The increase of $\mathrm{x}$ leads to the shift of the temperature of maximum dielectric permittivity towards lower temperatures. The samples with $\mathrm{x}=0.25$ and $\mathrm{x}=$ 0.35 exhibit very low values of dielectric losses up to about $370 \mathrm{~K}$. Dielectric losses for the samples with $\mathrm{x}=0.45$ are higher and the character of dielectric dispersion is different as compared to the samples with lower $\mathrm{x}$. The sample with $\mathrm{x}=0.45$ exhibits weak antiferromagnetism at room temperature.

\section{References}

[1] Lampis N., Sciau P., Lehman A.G., J. Phys.Condens. Mat., 12 (2000), 2367.

[2] Zhu W.Z., Kholkin A., Mantas P.Q., Baptista J.L., J. Eur. Ceram. Soc., 20 (2000), 2029.

[3] Shvorneva L.I., Venevtsev Y.N., J. Exp. Theor. Phys.+, 22 (1965), 722.

[4] Nomura S., Takabayashi H., Nakagawa T., Jpn. J. Appl. Phys., 7 (1968), 600.

[5] Brixel I., Rivera J.-P., Steiner A., Shmidt H., Ferroelectrics, 79 (1988), 201.

[6] Lampis N., Franchini C., Satta G., GeddoLehman A., Massida S., Phys. Rev. B., 69 (2004), 064412.

[7] Sanchez D.A. Ortega N., Kumar A., RoqueMalherbe R., Polanco R., Scott J.F., Katiyar R.S., Aip Adv., 1 (2011), 042169.

[8] Evans D.M., Schilling A., Kumar A., Sanchez D., Ortega N., Arredondo M., Katiyar R.S., Gregg J.M., ScotT J.F., Nat. Commun., 4 (2013), 1534.

[9] Sanchez D.A., Ortega N., Kumar A., Sreenivasulu G., Kattiyar R.S., Scott J.F., Evans D.M., Arredondo-Arechavala M., Schilling A., Gregg J.M., J. Appl. Phys., 113 (2013), 074105.

[10] Niemiec P., SKulski R., BocheneK D., WawrzaŁA P., Arch. Metall. Mater, 58 (2013) 1361. 